\title{
Acúmulo e desaparecimento de forragem e variações na estrutura de pastos de capim-xaraés submetidos a intensidades de pastejo em lotação intermitente
}

\author{
Accumulation and disappearance of forage and changes in the \\ pasture structure of xaraes palisadegrass subjected to grazing \\ intensities and intermittent stocking
}

\author{
Leandro Galzerano $^{1 *}$; Euclides Braga Malheiros ${ }^{2}$; Elisamara Raposo ${ }^{3}$; Eliane da \\ Silva Morgado ${ }^{4}$; Ana Claudia Ruggieri ${ }^{2}$
}

\begin{abstract}
Resumo
O objetivo deste trabalho foi avaliar os efeitos de índices de área foliar residual (IAFr), anos de avaliação e ciclos de pastejo sobre o acúmulo e desaparecimento de forragem e variações na estrutura de pastos de capim-xaraés sob pastejo em lotação intermitente, em dois verões agrostológicos. O experimento foi conduzido na Faculdade de Ciências Agrárias e Veterinária da Unesp, Câmpus de Jaboticabal, SP e as intensidades de pastejos foram definidas por quatro IAFr: 0,$8 ; 1,3 ; 1,8$ e 2,3. Quando o dossel interceptou $95 \%$ da luz incidente, os animais foram colocados no piquete para o pastejo e permaneceram até que o IAFr alvo foi alcançado. Os pastejos foram realizados por vacas da raça Holandesa (Bos taurus taurus L.) não lactantes, utilizando-se a técnica de mob-stocking. Foram avaliadas a altura do dossel, acúmulo, desaparecimento e componentes morfológicos da forragem e período de descanso. Índices de área foliar residual de 1,3 a 1,8 são os que melhores respostas apresentaram em relação ao acúmulo e desaparecimento de forragem e estrutura do pasto. Observou-se variabilidade de respostas no acúmulo e desaparecimento de forragem e estrutura dos pastos em relação aos anos de avaliação e ciclos de pastejo dentro de cada ano. Palavras-chave: Altura do dossel, Brachiaria, IAFr, interceptação de luz, período de descanso, Urochloa
\end{abstract}

\begin{abstract}
The aim of this study was to evaluate the effects of residual leaf area index (rLAI), years of evaluation and grazing cycles on the accumulation and disappearance of forage, and changes in the pasture structure of xaraés palisadegrass submitted to grazing intensities and intermittent stocking in two summers. The experiment was carried out at the Faculdade de Ciências Agrárias e Veterinária of Unesp, Campus of Jaboticabal, SP and the intensities of grazing were defined by four rLAI: 0.8, 1.3, 1.8 and 2.3. When the canopy intercepted $95 \%$ of incident light, the animals were placed on the pasture for grazing and kept until the rLAI target has been reached. Pastures were grazed by non-lactating Holstein cows (Bos Taurus Taurus L.), using the technique of mob-stocking. It was evaluated the canopy height, accumulation, disappearance and morphological components of forage and rest period. Residual leaf area index from
\end{abstract}

\footnotetext{
${ }^{1}$ Dr. em Zootecnia pela Universidade Estadual Paulista "Júlio de Mesquita Filho", UNESP, Campus de Jaboticabal, Via de Acesso Prof. Paulo Donato Castellane s/n, CEP 14884-900, Jaboticabal, SP. E-mail: galzeranorural@hotmail.com

2 Profs. da UNESP, Campus de Jaboticabal, Jaboticabal, SP. E-mail: euclides@fcav.unesp.br; acruggieri@fcav.unesp.br

${ }^{3}$ Discente do Programa de Pós-graduação em Zootecnia, UNESP, Campus de Jaboticabal, Jaboticabal, SP. E-mail: foxelisa@, hotmail.com

${ }^{4}$ Pós-doutoranda, UNESP, Campus de Jaboticabal, Jaboticabal, SP. Bolsista da FAPESP. E-mail: eliane_morgado@hotmail.com

* Autor para correspondência
} 
1.3 to 1.8 are the best in the accumulation and disappearance of forage and pasture structure. It is observed variability of the accumulation and disappearance of forage and pasture structure for years of assessment and grazing cycles within each year.

Key words: Brachiaria, canopy height, light interception, rest period, rLAI, Urochloa

\section{Introdução}

Nos últimos anos, observa-se progressos significativos sobre a compreensão dos fatores condicionantes da produção de forragem em pastos tropicais. Basicamente, as pesquisas têm enfocado o uso de tratamentos experimentais visando o controle rígido da estrutura do dossel, na tentativa de produzir informações consistentes e passíveis de serem reproduzidas nas diferentes condições edafoclimáticas do país (SBRISSIA; DA SILVA; NASCIMENTO JUNIOR, 2007). Fatores ambientais, como luz, temperatura, água e nutrientes são responsáveis por mudanças nos atributos de crescimento e estrutura da planta e o processo de pastejo permite resposta para as adaptações a essas mudanças. De acordo com Pedreira, Pedreira e Da Silva (2007), estratégias de pastejo afetam as características da planta forrageira, e a utilização de interceptação luminosa como referência de acompanhamento do processo de rebrotação permite que a forragem seja colhida (por corte ou pastejo) sempre em uma mesma condição fisiológica. No entanto, métodos tradicionais de uso de estratégias de pastejo baseadas em calendário para colheita de gramíneas tropicais, com períodos fixos e predeterminados de rebrotação, são inflexíveis e generalistas ao extremo. Segundo Parsons et al. (1988), na otimização da produção de um pasto, tanto em lotação contínua quanto intermitente, o manejo deve estar focado no entendimento entre a área foliar residual para fotossíntese e crescimento vegetal e a necessidade de remoção de tecido foliar, antes de sua senescência.

O objetivo deste trabalho foi avaliar os efeitos de índices de área foliar residual, anos de avaliação e ciclos de pastejo sobre o acúmulo e desaparecimento de forragem e variações na estrutura de pastos de capim-xaraés sob pastejo, durante dois verões agrostológicos (2009/2010 e 2010/2011).

\section{Material e Métodos}

O experimento foi conduzido na Faculdade de Ciências Agrárias e Veterinárias da Unesp, Câmpus de Jaboticabal, SP, localizado a 21 ${ }^{\circ} 15^{\prime} 22^{\prime \prime}$ de latitude Sul, e de 48 $18^{\prime} 58^{\prime \prime}$ de longitude Oeste, em dois verões agrostológicos, Ano 1 (outubro/2009 a abril/2010) e Ano 2 (outubro/2010 a abril/2011). A área total do experimento foi de 2.795,9 m², de pastos de Brachiaria brizantha cv. Xaraés, formada em dezembro de 2004 e dividida em 12 piquetes. As intensidades de pastejo foram definidas por quatro índices de área foliar residual (IAFr $=0,8 ; 1,3$; $1,8 ; 2,3)$, estimados com o aparelho analisador de dossel AccuPAR Model LP-80 PAR/LAI (Decagon devices $\left.^{\circledR}\right)$.

O solo da área experimental foi classificado como Latossolo Vermelho Distrófico, textura argilosa, horizonte A moderado, caulinítico hipoférrico com relevo suave ondulado (EMBRAPA, 2006). Amostragens de solo na camada de 0-20 cm de profundidade indicaram as seguintes propriedades químicas no Ano 1: $\mathrm{Ca}^{2+}: 27 ; \mathrm{Mg}^{2+}: 9,5 ; \mathrm{K}^{+}: 3,1$ mmol $/ \mathrm{dm}^{3}$; P (resina): 10,0 mg/dm³ $30: 22,5 \mathrm{~g} /$ $\mathrm{dm}^{3} ; \mathrm{pH}\left(\mathrm{CaCl}_{2}\right): 4,9$ e no Ano 2: $\mathrm{Ca}^{2+}: 24,5 ; \mathrm{Mg}^{2+}$ : 9,0; $\mathrm{K}^{+}: 4,2 \mathrm{mmol}_{\mathrm{c}} / \mathrm{dm}^{3}$; P (resina): $8,0 \mathrm{mg} / \mathrm{dm}^{3}$; MO: $27,5 \mathrm{~g} / \mathrm{dm}^{3} ; \mathrm{pH}\left(\mathrm{CaCl}_{2}\right): 4,7$.

Em novembro de 2009 e 2010 foram realizadas calagem e adubação, em cobertura uma vez que o capim já se encontrava estabelecido. A calagem consistiu na aplicação de 1000 kg.ha-1 de calcário calcítico e a adubação na aplicação de $100 \mathrm{~kg} \cdot \mathrm{ha}^{-1}$ de nitrogênio $(\mathrm{N})$ na forma de sulfato de amônio e $100 \mathrm{~kg} \cdot \mathrm{ha}^{-1}$ de potássio $(\mathrm{K})$ na forma de cloreto de 
potássio, ambas em dose única, manualmente e a lanço.

O Clima da região é caracterizado como Aw pelo sistema de Köppen, com duas estações distintas, uma seca, abril a setembro e outra chuvosa, de outubro a março. No ano 1 a precipitação durante o período de coleta de dados foi de $1329 \mathrm{~mm}$ e temperatura média de $23,65^{\circ} \mathrm{C}$; no ano 2 a precipitação foi de $1458 \mathrm{~mm}$ e temperatura média de $23,4^{\circ} \mathrm{C}$, dados obtidos na Estação de Agrometeorologia da UNESP, Campus de Jaboticabal.

$\mathrm{O}$ delineamento experimental foi inteiramente casualizado em esquema fatorial $2 \times 4$ (dois anos e quatro IAFr), com três repetições, repetidos em 4 ciclos de pastejo (tempos). Foi analisado utilizando o procedimento para medidas repetidas no tempo.

Os pastejos foram realizados por vacas da raça Holandesa (Bos taurus taurus L.) não lactantes, com peso aproximado de $450 \mathrm{~kg}$, utilizando-se a técnica de mob-stocking (ALLEN et al., 2011). Os animais entraram nos piquetes com $95 \%$ de IL (interceptação de luz, radiação fotossinteticamente ativa) (BROUGHAM, 1956) e permaneceram até que o IAFr alvo fosse atingido (pós-pastejo). Os pastejos nas unidades experimentais ocorreram simultaneamente nas repetições dos IAFr avaliados e a lotação animal variava para atingir o IAFr alvo. $\mathrm{Na}$ ocasião do pastejo de imposição dos IAFr, outubro do Ano 1, as touceiras que não foram pastejadas pelos animais até o IAFr alvo, foram rebaixadas com auxílio de roçadeira costal. Durante os meses de junho a setembro de 2009 e 2010, caracterizado como período seco, foi realizado um pastejo e os IAFr foram mantidos.

A altura média do dossel foi obtida por 30 medições ao acaso por piquete com réguas com graduação em centímetros no pré e pós-pastejo.

A massa de forragem do pré e pós-pastejo foi obtida utilizando-se a altura do dossel comprimido, pelo uso do disco descendente (GONZALEZ; HUSSEY; CONRRAD, 1990). O método consiste em um disco com 28,0 cm de raio, área de $0,25 \mathrm{~m}^{2} \mathrm{e}$ peso de $0,782 \mathrm{~kg}$, equivalente a pressão de $3,175 \mathrm{~kg} /$ $\mathrm{m}^{2}$. O disco possui um orifício no meio, pelo qual passa uma haste com graduação em centímetros. A avaliação consistiu da introdução da ponta da haste do disco no pasto, de forma perpendicular, do topo para a base até o nível do solo quando então o disco era solto de forma a acomodar-se no topo do pasto, e altura do ponto amostrado era anotada. Foram realizadas 30 medições de altura do disco no pré e pós-pastejo por piquete. Com a média da altura do dossel comprimido de cada piquete, foram escolhidos dois pontos representativos dessa altura e a massa de forragem foi obtida pelo corte ao nível do solo de toda forragem, contida no interior de um aro metálico com $0,25 \mathrm{~m}^{2}$. O material fresco de cada amostra foi sub-amostrado e realizado o fracionamento em material morto, lâminas foliares e colmos+bainhas e em seguida, levado para secagem, em estufa de circulação de ar forçada, a $55^{\circ} \mathrm{C}$, por 72 horas.

$\mathrm{O}$ acúmulo de forragem em $\mathrm{kg} \cdot \mathrm{ha}^{-1}$ de MS foi obtido por meio da diferença entre a massa de forragem do pré-pastejo atual e do pós-pastejo anterior e o desaparecimento de forragem $\mathrm{kg} \cdot \mathrm{ha}^{-1}$ de MS pela diferença entre a massa de forragem do pré-pastejo e do pós-pastejo do mesmo ciclo.

$\mathrm{O}$ período de descanso entre pastejos foi $\mathrm{o}$ número de dias entre dois pastejos sucessivos.

A análise estatística foi realizada utilizando o procedimento para modelos mistos do SAS (2008) (Statistical Analysis System), versão 9.2. Nas comparações entre níveis de tempo (ciclo de pastejo) e índice de área foliar residual (IAFr) utilizou-se contrastes ortogonais polinomiais $\left(1^{\circ}, 2^{\circ}\right.$ e $3^{\circ}$ grau) (LITTELL et al., 2006).

\section{Resultados e Discussão}

A altura do dossel no pré-pastejo, no Ano 2, apresentou médias superiores ao Ano 1, independentemente do IAFr (Tabela 1). No Ano 1, não houve efeito do IAFr e, no Ano 2, houve efeito quadrático $(\mathrm{P}<0,05)$. Quanto aos ciclos de pastejo, o Ano 2 apresentou média superior ao Ano $1(\mathrm{P}<0,05)$, em todos os ciclos de pastejo (Tabela 2$)$. 
O efeito do ciclo de pastejo foi quadrático no Ano 1 e linear no Ano 2. A maior altura do dossel no pré-pastejo encontrada no Ano 1 foi de 32,94 cm no ciclo de pastejo 4 e no Ano 2 foi de $55,02 \mathrm{~cm}$ também no ciclo de pastejo 4. Após o primeiro ano de avaliação, as mudanças na estrutura dos pastos fez com que as alturas variassem entre os Anos e IAFr. Os colmos remanescentes dos pastejos no Ano 1 e ação do clima no Ano 2 contribuíram para o aumento na altura do dossel devido ao alongamento dos colmos sobreviventes e surgimento de novas folhas. Nos pastejos menos intensos, foi maior a quantidade de colmos remanescentes que não foram consumidos pelaos animais. O IAF tem sido utilizado com bastante frequência nos últimos anos no Brasil como estratégia para interrupção do pastejo em experimentos em lotação intermitente e os resultados tem mostrado eficiência do uso dessa estratégia no manejo de pastos (LIMA SANTOS, 2009; CUTRIM JUNIOR et al., 2010; SILVA et al., 2013). Os maiores valores encontrados no ciclo de pastejo 4, no Ano 2, foi resultado do acúmulo de colmos durante os ciclos anteriores pois em pastejos menos intensos, a quantidade de material remanescente é maior o que dá a possibilidade dos animais selecionarem mais folhas em vez de colmos. Outro efeito pode ser em função da mudança nas condições climáticas pois no mês de março do Ano 2 ocorreu alta precipitação pluvial (496 mm), com 24 dias de chuva e, portanto, baixa insolação. A baixa insolação estimulou as plantas a alongarem os colmos o que resultou em maior altura do dossel. Pedreira, Pedreira e Da Silva (2007), em trabalho com capim-xaraés e estratégias de pastejo de 95 e $100 \%$ de interceptação de luz e período de descanso fixo de 28 dias, encontraram altura média do dossel associada a 95\% de interceptação de luz de $29,5 \mathrm{~cm}$.

A altura do dossel no pós-pastejo foi maior no Ano 2, independentemente do IAFr (Tabela 1). No Ano 1, o efeito do IAFr foi linear, com valores de 11,60 a 23,50 cm nos IAFr 0,8 e 2,3 respectivamente e, no Ano 2, quadrático $(\mathrm{P}<0,05)$ com valores de $20,66 \mathrm{~cm}$ a $37,30 \mathrm{~cm}$. Em relação aos ciclos de pastejo, a altura foi maior no Ano $2(\mathrm{P}<0,05)$, independentemente do ciclo de pastejo (Tabela 2). No Ano 1, o ciclo de pastejo não apresentou efeito $(\mathrm{P}>0,05)$ e no Ano 2, houve efeito linear, com aumento de $10 \mathrm{~cm}$ do ciclo de pastejo 1 para o ciclo de pastejo 4 .

Tabela 1. Médias de altura do dossel (pré e pós-pastejo) e período de descanso de pastos de capim-xaraés submetidos a intensidades de pastejo, para interação ano $\times$ índice de área foliar residual.

\begin{tabular}{|c|c|c|c|c|c|}
\hline \multirow{2}{*}{ Variável } & \multicolumn{4}{|c|}{ Índice de área foliar residual } & \multirow{2}{*}{ C. Pol. ${ }^{*}$} \\
\hline & 0,8 & 1,3 & 1,8 & 2,3 & \\
\hline Altura do dossel $(\mathrm{cm})$ & \multicolumn{4}{|c|}{ pré-pastejo } & \\
\hline Ano 1 & $30,41 \mathrm{~B}^{(1)}$ & $30,41 \mathrm{~B}$ & $31,80 \mathrm{~B}$ & $31,76 \mathrm{~B}$ & ns \\
\hline Ano 2 & $44,94 \mathrm{~A}$ & $50,78 \mathrm{~A}$ & $54,10 \mathrm{~A}$ & $53,40 \mathrm{~A}$ & Quadrático \\
\hline \multicolumn{6}{|c|}{ pós-pastejo } \\
\hline Ano 1 & $11,60 \mathrm{~B}$ & $16,26 \mathrm{~B}$ & $19,43 B$ & $23,50 \mathrm{~B}$ & Linear \\
\hline Ano 2 & $20,66 \mathrm{~A}$ & $27,64 \mathrm{~A}$ & $34,49 \mathrm{~A}$ & $37,30 \mathrm{~A}$ & Quadrático \\
\hline \multicolumn{6}{|l|}{ Período de descanso (dias) } \\
\hline Ano 1 & 33,12 & 29,25 & 28,91 & 30,08 & ns \\
\hline Ano 2 & 31,75 & 30,25 & 27,25 & 29,08 & Quadrático \\
\hline
\end{tabular}

${ }^{(1)}$ Médias seguidas da mesma letra, na coluna, não diferem entre si, pelo teste $\mathrm{F}$ a $5 \%$ de probabilidade. ${ }^{*} \mathrm{C}$. Pol.= contraste polinomial. ns= não significativo a $5 \%$ de probabilidade.

Fonte: Elaboração dos autores. 
Tabela 2. Médias de altura do dossel (pré e pós-pastejo) e período de descanso de pastos de capim-xaraés submetidos a intensidades de pastejo, para interação ano $\times$ ciclo de pastejo.

\begin{tabular}{|c|c|c|c|c|c|}
\hline \multirow{2}{*}{ Variável } & \multicolumn{4}{|c|}{ Ciclo de pastejo } & \multirow{2}{*}{ C. Pol.* } \\
\hline & 1 & 2 & 3 & 4 & \\
\hline Altura do dossel $(\mathrm{cm})$ & \multicolumn{4}{|c|}{ pré-pastejo } & \multirow{3}{*}{$\begin{array}{l}\text { Quadráticc } \\
\text { Linear }\end{array}$} \\
\hline Ano 1 & $32,27 \mathrm{~B}^{(1)}$ & $29,66 \mathrm{~B}$ & $29,52 \mathrm{~B}$ & $32,94 \mathrm{~B}$ & \\
\hline Ano 2 & $48,30 \mathrm{~A}$ & $47,38 \mathrm{~A}$ & $52,52 \mathrm{~A}$ & $55,02 \mathrm{~A}$ & \\
\hline \multicolumn{6}{|c|}{ pós-pastejo } \\
\hline Ano 1 & $16,69 \mathrm{~B}$ & $17,37 \mathrm{~B}$ & $16,99 \mathrm{~B}$ & $19,74 \mathrm{~B}$ & ns \\
\hline Ano 2 & $24,12 \mathrm{~A}$ & $27,01 \mathrm{~A}$ & $34,20 \mathrm{~A}$ & $34,76 \mathrm{~A}$ & Linear \\
\hline \multicolumn{6}{|l|}{ Período de descanso (dias) } \\
\hline Ano 1 & $28,45 \mathrm{~A}$ & $27,33 \mathrm{~A}$ & $28,16 \mathrm{~B}$ & $37,41 \mathrm{~A}$ & Quadrático \\
\hline Ano 2 & $23,83 \mathrm{~B}$ & $24,50 \mathrm{~A}$ & $34,00 \mathrm{~A}$ & $36,00 \mathrm{~A}$ & Linear \\
\hline
\end{tabular}

${ }^{(1)}$ Médias seguidas da mesma letra, na coluna, não diferem entre si, pelo teste $\mathrm{F}$ a $5 \%$ de probabilidade. ${ }^{*} \mathrm{C}$. Pol.= contraste polinomial. ns= não significativo a $5 \%$ de probabilidade.

Fonte: Elaboração dos autores.

$\mathrm{Na}$ interação IAFr $\times$ ciclo de pastejo (Tabela $3)$, todos os ciclos de pastejo apresentaram efeito linear $(\mathrm{P}<0,05)$. O IAFr 1,3 apresentou efeito linear $(\mathrm{P}<0,05)$ dentro dos ciclos de pastejo, e variou de 18,43 a 27,16 cm do ciclo de pastejo 1 para o ciclo de pastejo 4, respectivamente. Os demais IAFr não foram significativos. As diferenças encontradas na altura do dossel no pós-pastejo podem ser consequências dos mesmos efeitos registrados no pré-pastejo como, mudanças na estrutura do dossel, resultante das intensidades de pastejo e ação do clima. Não foi obtido valores de ângulo foliar, mas, visivelmente foi possível observar que no Ano 2, as folhas estavam mais eretas que no Ano 1. Segundo Bernardes (1987), a distribuição vertical e horizontal das folhas associada ao ângulo foliar, são os aspectos morfológicos que estão diretamente ligados a interceptação de luz em comunidades vegetais. No ciclo de pastejo 3 do Ano 2, o período de insolação diminuiu e resultou em florescimento principalmente nos pastos de IAFr 1,8 e 2,3, o que fez com que o colmo se alongasse contribuindo para aumento acentuado na altura do dossel. Braga et al. (2006) em trabalho com capim-marandu e ofertas de forragem encontraram que a altura do dossel no pós-pastejo foi menor na menor intensidade de pastejo e que com as demais intensidades houve aumento progressivo da altura ao longo do experimento $(21$ a $50 \mathrm{~cm})$. 
Tabela 3. Médias das características de pastos de capim-xaraés submetidos a intensidades de pastejo, para interação índice de área foliar $\times$ ciclo de pastejo.

\begin{tabular}{|c|c|c|c|c|c|c|}
\hline \multicolumn{7}{|c|}{ pré-pastejo } \\
\hline \multirow{7}{*}{$\begin{array}{l}\text { Massa de forragem } \\
\text { total } \\
\left(\mathrm{kg} \cdot \mathrm{ha}^{-1} \text { de MS) }\right.\end{array}$} & \multirow{2}{*}{ IAFr } & \multicolumn{4}{|c|}{ Ciclo de pastejo } & \multirow{2}{*}{ C. Pol. ${ }^{*}$} \\
\hline & & 1 & 2 & 3 & 4 & \\
\hline & 0,8 & 5381,57 & 7422,15 & 9532,30 & 8467,15 & Linear \\
\hline & 1,3 & 7055,81 & 8878,70 & 10070,35 & 9111,01 & ns \\
\hline & 1,8 & 9733,36 & 8140,90 & 8721,98 & 10516,11 & ns \\
\hline & 2,3 & 9533,35 & 7935,55 & 9951,45 & 11438,61 & ns \\
\hline & C. Pol. & Linear & ns & ns & ns & \\
\hline \multirow{5}{*}{$\begin{array}{l}\text { Massa de folha } \\
\text { (kg.ha-1 }^{-1} \text { de MS) }\end{array}$} & 0,8 & 2899,70 & 3694,72 & 4482,22 & 3939,82 & ns \\
\hline & 1,3 & 3552,30 & 4228,70 & 4518,65 & 3877,05 & ns \\
\hline & 1,8 & 5048,33 & 3782,70 & 3873,26 & 4510,23 & ns \\
\hline & 2,3 & 4434,30 & 3564,25 & 4748,08 & 4965,78 & ns \\
\hline & C. Pol. & Linear & ns & ns & ns & \\
\hline \multirow{5}{*}{$\begin{array}{l}\text { Massa de colmo } \\
\left(\text { kg.ha }^{-1} \text { de MS }\right)\end{array}$} & 0,8 & 1831,65 & 2442,92 & 2987,92 & 2544,65 & ns \\
\hline & 1,3 & 2299,91 & 2769,30 & 3333,88 & 2920,16 & ns \\
\hline & 1,8 & 3447,75 & 2656,01 & 2955,26 & 3503,21 & ns \\
\hline & 2,3 & 3131,70 & 2791,95 & 3109,58 & 4002,55 & ns \\
\hline & C. Pol. & Linear & ns & ns & Linear & \\
\hline \multirow{5}{*}{$\begin{array}{l}\text { Massa de material } \\
\text { morto } \\
\text { (kg.ha- }{ }^{-1} \text { de MS) }\end{array}$} & 0,8 & 650,22 & 1284,50 & 2062,17 & 1982,67 & Linear \\
\hline & 1,3 & 1203,65 & 1880,70 & 2217,81 & 2313,80 & Linear \\
\hline & 1,8 & 1237,28 & 1702,18 & 1993,46 & 2502,68 & Linear \\
\hline & 2,3 & 1967,38 & 1702,18 & 2093,83 & 2470,28 & ns \\
\hline & C. Pol. & Linear & ns & ns & ns & \\
\hline \multicolumn{7}{|c|}{ pós-pastejo } \\
\hline \multirow{5}{*}{$\begin{array}{l}\text { Altura do dossel } \\
(\mathrm{cm})\end{array}$} & 0,8 & 13,25 & 15,70 & 16,75 & 18,80 & ns \\
\hline & 1,3 & 18,43 & 20,03 & 22,18 & 27,16 & Linear \\
\hline & 1,8 & 23,40 & 23,58 & 30,30 & 30,56 & $\mathrm{~ns}$ \\
\hline & 2,3 & 26,55 & 29,45 & 33,15 & 32,46 & ns \\
\hline & C. Pol. & Linear & Linear & Linear & Linear & \\
\hline \multirow{5}{*}{$\begin{array}{l}\text { Massa de material } \\
\text { morto } \\
\left(\mathrm{kg} \cdot \mathrm{ha}^{-1} \text { de MS) }\right.\end{array}$} & 0,8 & 983,87 & 1758,75 & 1408,65 & 2295,87 & Linear \\
\hline & 1,3 & 1879,76 & 1835,41 & 1808,76 & 2597,51 & ns \\
\hline & 1,8 & 2022,76 & 2066,51 & 2132,53 & 2200,91 & ns \\
\hline & 2,3 & 1853,48 & 2450,80 & 2278,58 & 2031,55 & ns \\
\hline & C. Pol. & Quadrático & ns & Linear & ns & \\
\hline \multirow{5}{*}{$\begin{array}{l}\text { Acúmulo de } \\
\text { forragem } \\
\left(\mathrm{kg} \cdot \mathrm{ha}^{-1} \text { de MS) }\right.\end{array}$} & 0,8 & 2935,32 & 4526,42 & 4661,05 & 4017,70 & ns \\
\hline & 1,3 & 2971,41 & 3702,36 & 4600,88 & 3469,01 & ns \\
\hline & 1,8 & 5086,36 & 1732,70 & 2323,61 & 3625,30 & Quadrático \\
\hline & 2,3 & 4698,41 & 1659,86 & 2974,43 & 4229,30 & Quadrático \\
\hline & C. Pol. & ns & Linear & ns & $\mathrm{ns}$ & \\
\hline \multirow{5}{*}{$\begin{array}{l}\text { Desaparecimento de } \\
\text { folha } \\
\left(\mathrm{kg} \cdot \mathrm{ha}^{-1} \text { de MS }\right)\end{array}$} & 0,8 & 2190,37 & 2629,17 & 3189,55 & 2344,52 & ns \\
\hline & 1,3 & 2299,65 & 2813,85 & 3129,76 & 2273,98 & ns \\
\hline & 1,8 & 3407,40 & 1927,50 & 2006,03 & 2691,35 & Quadrático \\
\hline & 2,3 & 2495,21 & 1559,83 & 2433,88 & 2454,05 & ns \\
\hline & C. Pol. & $\mathrm{ns}$ & Linear & ns & ns & \\
\hline
\end{tabular}

${ }^{(1)}$ Médias seguidas da mesma letra, na coluna, não diferem entre si, pelo teste $\mathrm{F}$ a $5 \%$ de probabilidade. ${ }^{*}$

C. Pol. $=$ contraste polinomial. ns= não significativo a $5 \%$ de probabilidade.

Fonte: Elaboração dos autores. 
A massa total no pré-pastejo teve efeito linear do IAFr com valores de $7700,79 \mathrm{~kg} \cdot \mathrm{ha}^{-1}$ de $\mathrm{MS}$ no IAFr 0,8 e 9714,74 kg.ha-1 de MS no IAFr 2,3 (Tabela 4). No Ano 2 a massa total foi superior ao Ano $1(\mathrm{P}<0,05)$, nos ciclos de pastejo 1,3 e 4 (Tabela 5). Não houve efeito do ciclo de pastejo no Ano 1 e no Ano 2 o efeito foi cúbico $(\mathrm{P}<0,05)$ (Tabela 5).

Tabela 4. Efeitos do índice de área foliar residual na massa de forragem de pastos de capim-xaraés submetidos a intensidades de pastejo.

\begin{tabular}{|c|c|c|c|c|c|}
\hline \multirow{2}{*}{$\begin{array}{l}\text { Massa de forragem } \\
\left(\mathrm{kg} \cdot \mathrm{ha}^{-1} \text { de MS }\right)\end{array}$} & \multicolumn{4}{|c|}{ Índice de área foliar residual } & \multirow{2}{*}{ C. Pol. } \\
\hline & 0,8 & 1,3 & 1,8 & 2,3 & \\
\hline & \multicolumn{4}{|c|}{ pré-pastejo } & \\
\hline Total & 7700,79 & 8778,97 & 9278,09 & 9714,74 & Linear \\
\hline Folha & 3754,11 & 4044,17 & 4303,63 & 4428,10 & Linear \\
\hline Colmo & 2451,78 & 2830,81 & 3140,56 & 3258,94 & Linear \\
\hline \multirow[t]{2}{*}{ Material morto } & 1494,23 & 1903,99 & 1833,90 & 2027,71 & Linear \\
\hline & \multicolumn{4}{|c|}{ pós-pastejo } & \\
\hline Total & 4664,06 & 5781,12 & 6596,37 & 7020,55 & Linear \\
\hline Folha & 1165,71 & 1498,20 & 1837,23 & 2109,02 & Linear \\
\hline Colmo & 1886,58 & 2252,55 & 2653,44 & 2757,95 & Linear \\
\hline Material morto & 1611,78 & 2030,36 & 2105,68 & 2153,60 & Linear \\
\hline
\end{tabular}

${ }^{*} \mathrm{C}$. Pol.= contraste polinomial.

Fonte: Elaboração dos autores.

Os valores encontrados no Ano 2 (Tabela 5) são resultados das condições impostas ao dossel no primeiro e também consequencia do acúmulo de material durante os meses de maiooutubro de 2010. Com a chegada do período das águas e avaliação do Ano 2 do experimento, surgiram rebrotações no topo do dossel, à partir do material remanescente no pasto. O processo de rebrotação à partir do resíduo, resultou em aumento na altura do dossel e massa de forragem no pré-pastejo. O IAFr 0,8 que menor resíduo apresentou, resultou em rebrotação de materiais mais novos, provenientes da base do dossel e de novos perfilhos.

No início do período das águas, alguns perfilhos vivos estavam revestidos por bainhas de folhas mortas acumuladas durante o período seco o que contribuiu para um ambiente luminoso desfavorável ao aproveitamento máximo da luz e, portanto, a estratégia adotada pela planta foi a de alongar os colmos.

A massa de folha no pré-pastejo, respondeu de forma linear $(\mathrm{P}<0,05)$ ao IAFr (Tabela 4$)$. No Ano 2 a massa de folha no pré-pastejo apresentou média superior ao Ano 1, no ciclo de pastejo 3 (Tabela $5)$, nos demais ciclos de pastejo não houve efeito $(\mathrm{P}>0,05)$ esse fato pode ser devido a angulação das folhas que visualmente foi possível notar que no Ano 2 os ângulos foliares e comprimento das folhas, principalmente no ciclo de pastejo 3 foram maiores que no Ano 1 e isso fez com que fosse necessária uma quantidade maior de folhas para interceptar os $95 \%$ de interceptação de luz e interrupção do processo de rebrotação. No Ano 1, o efeito do ciclo de pastejo na massa de folha foi quadrático e no Ano 2, cúbico. 
Tabela 5. Médias de massa, acúmulo e desaparecimento de forragem, de pastos de capim-xaraés submetidos a intensidades de pastejo, para interação ano $\times$ ciclo de pastejo.

\begin{tabular}{|c|c|c|c|c|c|c|}
\hline \multirow{2}{*}{\multicolumn{2}{|c|}{$\begin{array}{l}\text { Massa de forragem } \\
\left(\mathrm{kg} \cdot \mathrm{ha}^{-1} \text { de MS }\right)\end{array}$}} & \multicolumn{4}{|c|}{ Ciclo de pastejo } & \multirow{2}{*}{ C. Pol. ${ }^{*}$} \\
\hline & & 1 & 2 & 3 & 4 & \\
\hline \multirow{3}{*}{ Total } & \multicolumn{6}{|c|}{ pré-pastejo } \\
\hline & Ano 1 & $7134,35 \mathrm{~B}^{(1)}$ & $7601,75 \mathrm{~A}$ & $6767,73 \mathrm{~B}$ & $8241,37 \mathrm{~B}$ & ns \\
\hline & Ano 2 & $8717,70 \mathrm{~A}$ & $8586,89 \mathrm{~A}$ & $12370,30 \mathrm{~A}$ & $11525,07 \mathrm{~A}$ & Cúbico \\
\hline \multicolumn{7}{|l|}{ Folha } \\
\hline & Ano 1 & $4040,72 \mathrm{~A}$ & $3727,49 \mathrm{~A}$ & $3342,12 B$ & $4022,36 \mathrm{~A}$ & Quadrático \\
\hline & Ano 2 & $3926,59 \mathrm{~A}$ & $3907,69 \mathrm{~A}$ & $5468,98 \mathrm{~A}$ & $4624,07 \mathrm{~A}$ & Cúbico \\
\hline \multicolumn{7}{|l|}{ Colmo } \\
\hline & Ano 1 & $2328,14 \mathrm{~B}$ & $2428,85 \mathrm{~A}$ & $2055,60 \mathrm{~B}$ & $2640,20 \mathrm{~B}$ & $\mathrm{~ns}$ \\
\hline & Ano 2 & $3027,36 \mathrm{~A}$ & $2901,24 \mathrm{~A}$ & $4137,72 \mathrm{~A}$ & $3845,09 \mathrm{~A}$ & Cúbico \\
\hline \multicolumn{7}{|c|}{ Material morto } \\
\hline & Ano 1 & $765,49 \mathrm{~B}$ & $1445,40 \mathrm{~A}$ & $1370,00 \mathrm{~B}$ & 1578,81B & Linear \\
\hline & Ano 2 & $1763,77 \mathrm{~A}$ & $1777,95 \mathrm{~A}$ & $2763,63 \mathrm{~A}$ & $3055,90 \mathrm{~A}$ & Linear \\
\hline \multirow[t]{3}{*}{ Folha } & \multicolumn{6}{|c|}{ pós-pastejo } \\
\hline & Ano 1 & $1353,72 \mathrm{~A}$ & $1345,80 \mathrm{~B}$ & $1447,86 \mathrm{~B}$ & $1632,51 \mathrm{~B}$ & $\mathrm{~ns}$ \\
\hline & Ano 2 & $1417,24 \mathrm{~A}$ & $1740,89 \mathrm{~A}$ & $2150,31 \mathrm{~A}$ & $2131,98 \mathrm{~A}$ & Linear \\
\hline \multicolumn{7}{|c|}{ Acúmulo } \\
\hline & Ano 1 & $4510,25 \mathrm{~A}$ & $3125,59 \mathrm{~A}$ & 1938,21B & $3291,37 \mathrm{~B}$ & Quadrático \\
\hline & Ano 2 & $3335,51 \mathrm{~B}$ & $2685,08 \mathrm{~B}$ & $5341,77 \mathrm{~A}$ & $4379,28 \mathrm{~A}$ & Cúbico \\
\hline \multicolumn{7}{|c|}{ Desaparecimento de folha } \\
\hline & Ano 1 & $2686,99 \mathrm{~A}$ & $2298,37 \mathrm{~A}$ & $1810,95 \mathrm{~B}$ & $2389,82 \mathrm{~A}$ & Quadrático \\
\hline & Ano 2 & $2509,32 \mathrm{~A}$ & $2166,80 \mathrm{~A}$ & $3568,66 \mathrm{~A}$ & $2492,12 \mathrm{~A}$ & Cúbico \\
\hline \multicolumn{7}{|c|}{ Desaparecimento de colmo } \\
\hline & Ano 1 & $500,49 \mathrm{~A}$ & $498,82 \mathrm{~A}$ & $189,02 \mathrm{~B}$ & $662,29 \mathrm{~A}$ & ns \\
\hline & Ano 2 & $617,96 \mathrm{~A}$ & $115,64 \mathrm{~A}$ & $1320,94 \mathrm{~A}$ & $358,03 \mathrm{~A}$ & Cúbico \\
\hline
\end{tabular}

${ }^{(1)}$ Médias seguidas da mesma letra, na coluna, não diferem entre si, pelo teste $\mathrm{F}$ a $5 \%$ de probabilidade. ${ }^{*} \mathrm{C}$. Pol.= contraste polinomial. ns= não significativo a $5 \%$ de probabilidade.

Fonte: Elaboração dos autores.

A produção de folhas no pré-pastejo foi maior no Ano 2 mas o incremento de massa de colmo na mesma ocasião foi muito maior. $\mathrm{O}$ aumento geral de folhas do Ano 1 ao Ano 2 foi em torno de $700 \mathrm{~kg}$ enquanto que o aumento de colmo foi de aproximadamente $1100 \mathrm{~kg}$. Esse aumento de colmo fez com que a participação em porcentagem de folhas do Ano 1 para o Ano 2 diminuísse de 51,17\% para $44,07 \%$.

Levando-se em consideração que a característica desejável na massa de forragem total de um pasto é a elevada quantidade de folhas verdes e baixa quantidade de colmos, o IAFr 1,3 propiciou os melhores resultados pois a quantidade de massa de folhas no pré-pastejo no IAFr 1,3 foi superior ao IAFr 0,8 e próxima aos IAFr 1,8 e 2,3 no entanto, a quantidade de massa de colmo no pré-pastejo foi inferior aos IAFr 1,8 e 2,3 (Tabela 4). Lima Santos (2009) em trabalho com capim-tanzânia e estratégias de manejo focadas no IAFr como meta de saída dos animais dos pastos e interrupção da desfolhação, relatou que o uso do IAFr como estratégias de intensidades de pastejo promove mudanças na estrutura do dossel, sendo um critério efetivo para controlar e definir o manejo do pastejo.

O IAFr apresentou efeito linear $(\mathrm{P}<0,05)$ na 
massa de colmo no pré-pastejo (Tabela 4). No Ano 2 a massa de colmo no pré-pastejo apresentou média superior ao Ano 1 nos ciclos de pastejo 1, 3 e 4 (Tabela 5). Não houve efeito do ciclo de pastejo no Ano 1 e no Ano 2 o efeito foi cúbico $(\mathrm{P}<0,05)$. A participação do colmo em termos porcentuais na massa total de forragem do pré-pastejo aumentou de $31 \%$ no Ano 1 para 33\% no Ano 2. No início do período das águas, alguns perfilhos vivos estavam revestidos por bainhas de folhas mortas acumuladas durante o período seco o que contribuiu para um ambiente luminoso desfavorável ao aproveitamento máximo da luz e, portanto, a estratégia adotada pela planta foi a de alongar os colmos. Magalhães (2010) em trabalho com capim-xaraés sob estratégias de pastejo em lotação intermitente e ofertas de forragem de 4, 7, 10 e 13\% do peso corporal de vacas da raça Holandesa, encontrou que o maior resíduo pós-pastejo, imposto pela oferta de forragem de $13 \%$ do peso corporal, resultou em maior altura do dossel bem como maior quantidade de lâminas foliares no pré pastejo do último ciclo. Os resultados encontrados pela pesquisadora corroboram com os resultados encontrados neste trabalho e ratificam que dosséis mantidos sob pastejos menos intensos, resultam em maior altura do dossel aos 95\% de interceptação de luz provavelmente ocasionada pelo maior acúmulo de colmos.

$\mathrm{Na}$ massa de material morto no pré-pastejo, o efeito do IAFr foi linear $(\mathrm{P}<0,05)$ com valores de 1494,23 kg.ha-1 de MS no IAFr 0,8 e de 2027,71 kg.ha-1 de MS no IAFr 2,3 (Tabela 4). O Ano 2 apresentou valores superiores ao Ano 1 nos ciclos de pastejo 1, 3 e 4 e o efeito isolado do ciclo de pastejo foi linear $(\mathrm{P}<0,05)$ no Ano 1 e 2 (Tabela 5). Na interação IAFr $\times$ ciclo de pastejo (Tabela 3) houve efeito linear nos IAFr 0,8, 1,3 e 1,8. De maneira geral, massa de material morto no pré e póspastejos foram maiores no Ano 2. A porcentagem de massa de material morto no pré-pastejo foi de $17 \%$ no Ano 1 e $22 \%$ no Ano 2. Os pastejos menos intensos (IAFr 1,8 e 2,3) resultaram em maiores quantidades de massa de forragem remanescente no pasto (Tabela 4). O material verde não colhido pelos animais permanecia no pasto por longo tempo, o que ocasionava a senescência e morte natural desse material, aumentando a quantidade de material morto coletada nas amostras dos ciclos sucessivos. Já a menor quantidade de material morto no IAFr 0,8 no pré-pastejo (Tabela 4) pode ser explicada pela maior quantidade e qualidade da luz que chega a base do dossel e estimula o surgimento e desenvolvimento de novos perfilhos.

A massa total no pós-pastejo aumentou linearmente $(\mathrm{P}<0,05)$, com valores de 4664,06 kg.ha-1 de MS no IAFr 0,8 a 7020,55 kg.ha-1 de MS no IAFr 2,3 (Tabela 4). O efeito do ciclo de pastejo foi linear com valores de $5188,99 \mathrm{~kg} \cdot \mathrm{ha}^{-1}$ de MS no ciclo de pastejo 1 e 6896,20 kg.ha-1 de MS no ciclo de pastejo 4 (Tabela 6). Os menores IAFr resultaram em menores valores de massa total no pós-pastejo enquanto que os maiores IAFr resultaram em maiores valores. Segundo Da Silva e Pedreira (1997) altas ofertas de forragem resultam em níveis de utilização de apenas um terço da forragem ofertada, gerando perdas excessivas que diminuem a produtividade do sistema de produção como um todo.

A massa de folha no pós-pastejo aumentou linearmente $(\mathrm{P}<0,05)$ com valores de 1165,71 kg.ha ${ }^{-1}$ de MS e 2109,02 kg.ha-1 de MS nos IAFr 0,8 e 2,3, respectivamente (Tabela 4). Em relação ao ciclo de pastejo, no Ano 2 a massa de folha superior ao Ano 1 nos ciclos de pastejo 2, 3 e 4 (Tabela 5). Não houve efeito de ciclo de pastejo no Ano $1 \mathrm{e}$ no Ano 2 o efeito foi linear $(\mathrm{P}<0,05)$, com valores de 1417,24 kg.ha-1 de MS no ciclo de pastejo 1 e 2131,98 kg.ha-1 de MS no ciclo de pastejo 4. Os diferentes valores de massa de folha encontrados (Tabela 4) demonstram que as estratégias de pastejo impostas ao dossel (IAFr) foram atingidas.

$\mathrm{Na}$ massa de colmo no pós-pastejo, o IAFr apresentou efeito linear $(\mathrm{P}<0,05)$ com valores de 1886,58 kg.ha-1 de MS 1 e 2757,95 kg.ha-1 de MS nos IAFr 0,8 e 2,3, respectivamente (Tabela 4). O ciclo 
de pastejo apresentou efeito linear $(\mathrm{P}<0,05)$, com valores de 2118,54 kg.ha-1 de MS e 2732,48 kg.ha-1 de MS nos ciclos de pastejo 1 e 4, respectivamente (Tabela 5).

O IAFr 1,3 foi o que melhor resposta apresentou em relação ao material remanescente pós-pastejo no processo de rebrotação do pasto, sem que o ambiente luminoso no dossel fosse prejudicado, o que evitou o alongamento excessivo e acúmulo de massa de colmos. O acúmulo de colmos é fator negativo no manejo do pasto, pois é um componente pouco pastejado, principalmente quando lignificado, tornando-se de difícil apreensão e remoção pelos animais.

A massa de material morto no pós-pastejo aumentou linearmente $(\mathrm{P}<0,05)$ com valores de $1611,78 \mathrm{~kg} \cdot \mathrm{ha}^{-1}$ de MS no IAFr 0,8 e $2153 \mathrm{~kg} \cdot \mathrm{ha}^{-1}$ de MS no IAFr 2,3 (Tabela 4). O aumento da massa de material morto em relação aos ciclos de pastejo foi linear $(\mathrm{P}<0,05)$, com valores de $1684,78 \mathrm{~kg} \cdot \mathrm{ha}^{-1}$ de MS no ciclo de pastejo 1 e 2281,46 kg.ha ${ }^{-1}$ de MS no ciclo de pastejo 4 (Tabela 6). Na interação IAFr $\times$ ciclo de pastejo (Tabela 3 ), houve efeito linear no IAFr 0,8 e ciclo de pastejo 3 . No ciclo de pastejo $1 \mathrm{o}$ efeito foi quadrático. Nos demais ciclos de pastejo e IAFr não houve efeito. Em trabalho de intensidades de desfolhação de 10 e $20 \mathrm{~cm}$ de altura do dossel nas características estruturais e na produção de forragem do capim-marandu, Marcelino et al. (2006) encontraram que a maior intensidade de desfolha proporcionou maior renovação de tecidos foliares, que condicionou ao dossel perfilhos mais jovens, que se desenvolveram em ambiente com menos competição por luz.

A estratégia de $95 \%$ de interceptação de luz diminuiu a quantidade de material auto-sombreado e, portanto, a morte de tecidos. No entanto, a forragem que remanesceu no pasto, após os pastejos, inevitavelmente morreu depois de algum tempo, como resposta ao processo natural de senescência e morte dos tecidos. Esse material permaneceu junto ao dossel por algum tempo, antes de ser depositado no solo na forma de serrapilheira e foi colhido junto ao material fresco amostrado para quantificação da massa de forragem, o que pode ter contribuído no aumento da massa de material morto nos pastejos menos intensos (Tabela 4).

Quanto ao acúmulo de forragem, os ciclos de pastejo 1 e 2, no Ano 1 apresentaram média superior ao Ano 2 (Tabela 5). No Ano 1, o efeito de ciclo de pastejo foi quadrático e no Ano 2 cúbico $(\mathrm{P}>0,05)$. $\mathrm{Na}$ interação IAFr $\times$ ciclo de pastejo (Tabela 3), houve efeito quadrático do ciclo de pastejo nos IAFr 1,8 e 2,3. O IAFr apresentou efeito linear no ciclo de pastejo 2, com menor valor de 1659,86 kg.ha-1 de MS no IAFr 2,3. No ciclo de pastejo 3 do Ano 2 foi encontrado o maior acúmulo de forragem de 5341,77 kg.ha ${ }^{-1}$ de MS. Na mesma ocasião foi registrado o maior valor no desaparecimento de massa de folha de 3568,66 kg.ha-1 de MS, pois, com maior acúmulo de forragem, maior foi o desaparecimento de forragem para atingir o IAFr alvo.

O maior desaparecimento de massa de colmo de 1320,94 kg.ha-1 de MS (Tabela 5) foi registrado no Ano 2, ciclo de pastejo 3 , nessa mesma ocasião houve o maior acúmulo de forragem registrado durante o período experimental. Teoricamente os animais foram forçados a consumirem maior quantidade de colmos em comparação aos outros ciclos de pastejo até atingir o IAFr alvo.

No período de descanso, o IAFr não apresentou efeito no Ano 1 e apresentou efeito $(\mathrm{P}<0,05)$ quadrático no Ano 2 com maior valor no IAFr 0,8 de 31,75 dias e menor no IAFr 1,8 de 27,25 dias (Tabela 1). Quanto aos ciclo de pastejo, no Ano 1, o período de descanso apresentou média superior ao Ano 2, no ciclo de pastejo 1 (Tabela 2). O maior período de descanso encontrado no Ano 2, foi no ciclo de pastejo 3, de 34 dias. O efeito do ciclo de pastejo no Ano 1 foi quadrático com maior período de descanso no ciclo de pastejo 4 de 37,41 dias e menor valor no ciclo de pastejo 2 de 27,33 dias. No Ano 2 o efeito foi linear com valores de 23,83 dias no IAFr 0,8 e de 36,0 no IAFr 2,3. Uma vez que o 
acúmulo de forragem não diferiu entre os IAFr e os IAFr proporcionaram diferentes massa de forragem total no pós-pastejo, foi possível encontrar efeito $(\mathrm{P}<0,05)$ no período de descanso entre os IAFr. No Ano 2, o maior período de descanso foi no IAFr 0,8 , isso ocorreu pois a quantidade de material residual no IAFr 0,8 foi menor em comparação aos IAFr 1,8 e 2,3, e aumentou o período de descanso de 4 e 2 dias para atingir $95 \%$ de interceptação de luz em comparação aos IAFr 1,8 e 2,3 respectivamente.

\section{Conclusões}

Índices de área foliar residual de 1,3 a 1,8 são os que melhores respostas apresentam em relação ao acúmulo e desaparecimento de forragem e estrutura de pastos de capim-xaraés submetidos a intensidades de pastejo. Observa-se variabilidade de respostas no acúmulo e desaparecimento de forragem e estrutura dos pastos em relação aos anos de avaliação e ciclos de pastejo dentro de cada ano.

\section{Referências}

ALLEN, V. G.; BATELLO, C.; BERRETTA, E. J.; HODGSON, J.; KOTHMANN, M.; LI, X.; MCLVOR, J.; MILNE, J.; MORRIS, C.; PEETERS, A.; SANDERSON, M. An international terminology for grazing lands and grazing animals. Grass and Forage Science, Oxford, v. 66, n. 1, p. 2-28, 2011.

BERNARDES, M. S. Fotossíntese no dossel das plantas cultivadas. In: CASTRO, P. R. C. (Ed.). Ecofisiologia da produção agrícolas. Piracicaba: Associação Brasileira para Pesquisa de Potassa e do Fosfato, 1987. p. 13-48.

BRAGA, G. J.; PEDREIRA, C. G. S.; HERLING, V. R.; LUZ, P. H. C.; LIMA, C. G. Sward structure and herbage yield of rotationally stocked pastures of 'Marandu' palisadegrass [Brachiaria brizantha (A.Rich.) Stapf] as affected by herbage allowance. Scientia Agricola, Piracicaba, v. 63, n. 2, p. 121-129, 2006.

BROUGHAM, R. W. Effects of intensity of defoliation on regrowth of pasture. Australian Journal Agricultural Research, Collingwood, v. 7, n. 5, p. 377-387, 1956.

CUTRIM JUNIOR, J. A. A.; CÂNDIDO, M. J. D.; VALENTE, B. S. M.; CARNEIRO, M. S. S.; CARNEIRO, H. A. V.; CIDRÃO, P. M. L. Fluxo de biomassa em capim-tanzânia sob três frequências de desfolhação e dois resíduos pós-pastejo. Revista Brasileira de Saúde e Produção Animal, Salvador, v. 11, n. 3, p. 618-629, 2010.

DA SILVA, S. C.; PEDREIRA, C. G. S. Princípios de ecologia aplicados ao manejo de pastagem. In: SIMPÓSIO SOBRE ECOSSISTEMAS DE PASTAGENS, 3., Jaboticabal, 1997. Anais... Jaboticabal: FUNEP, 1997. p. 1-62.

EMPRESA BRASILEIRA DE PESQUISA AGROPECUÁRIA - EMBRAPA. Sistema brasileiro de classificação de solos. Brasília: EMBRAPA, 2006. 306 p.

GONZALEZ, M. A.; HUSSEY, M. A.; CONRRAD, B. E. Plant height, disk and capacitance meters used to estimate Bermuda grass herbage mass. Agronomy Journal, Madison, v. 82, n. 5, p. 861-864, 1990.

LIMA SANTOS, N. Avaliação do Capim-tanzânia manejado com diferentes IAF residuais sob lotação rotacionada por cabras Boer X Saanen. 2009. Dissertação (Mestrado em Zootecnia) - Faculdade de Ciências Agrárias e Veterinárias, Universidade Estadual Paulista Júlio de Mesquita Filho, Jaboticabal.

LITTELL, R. C.; MILLIKEN, G. A.; STROUP, W. W.; WOLFINGER, R. D.; SCHABENBERGER, O. Sas for mixed models. 2. ed. Cary: SAS Institute Inc., 2006. 813 p.

MAGALHÃES, M. A. Características morfogênicas, estruturais e composição química de cultivares de Brachiaria submetidas a niveis de oferta de forragem sob pastejo rotativo. 2010. Tese (Doutorado em Zootecnia) - Faculdade de Ciências Agrárias e Veterinárias. Universidade Estadual Paulista Júlio de Mesquita Filho, Jaboticabal.

MARCELINO, K. R. A.; NASCIMENTO JÚNIOR, D.; SILVA, S. C.; EUCLIDES, V. P. B.; FONSECA, D. M. Características morfogênicas e estruturais e produção de forragem do capim-Marandu submetido a intensidades e freqüências de desfolhação. Revista Brasileira de Zootecnia, Viçosa, v. 35, n. 6, p. 2243-2252, 2006.

PARSONS, A. J.; JOHNSON, I. R.; HARVEY, A. Use of a model to optimize the interaction between frequency and severity of intermittent defoliation and to provide a fundamental comparison of the continuous and intermittent defoliation of grass. Grass and Forage Science, Oxford, v. 43, n. 4, p. 49-59, 1988.

PEDREIRA, B. C.; PEDREIRA, C. G. S.; DA SILVA, S. C. Estrutura do dossel e acúmulo de forragem de Brachiaraia brizantha cultivar Xaraés em resposta a estratégias de pastejo. Pesquisa Agropecuária Brasileira, Brasília, v. 42, n. 2, p. 281-287, 2007.

SAS Institute. SAS/STAT 9.2 User's guide. SAS Institute Inc, Cary, NC, 2008. 
SBRISSIA, A. F.; SILVA, S. C. da; NASCIMENTO JUNIOR, D. Ecofisiologia de plantas forrageiras e o manejo do pastejo. In: SIMPÓSIO SOBRE MANEJO DA PASTAGEM, 24., 2007, Piracicaba. Anais... Piracicaba, 2007. p. 1-27.
SILVA, W. L.; GALZERANO, L.; REIS, R. A.; RUGGIERI, A. C. Structural characteristics and forage mass of Tifton 85 pastures managed under three postgrazing residual leaf areas. Revista Brasileira de Zootecnia, v. 42, n. 4, p. 238-245, 2013. 